\title{
Title: Effect of the radiation protective apron on the response of active and passive personal dosemeters used in interventional radiology and cardiology
}

\section{Authors}

Mercè Ginjaume $^{1}$, Eleftheria Carinou ${ }^{2}$, Marcin Brodecki $^{3}$, Isabelle Clairand ${ }^{4}$, Joanna Domienik ${ }^{3}$, Lukas Exner ${ }^{5}$, Paolo Ferrari ${ }^{6}$, Zoran Jovanovic ${ }^{7}$, Dragana Krstic ${ }^{7}$, Sara Principi ${ }^{1}$,Olivier Van Hoey $^{8}$, Filip Vanhavere ${ }^{8}$

\begin{abstract}
In fluoroscopy guided interventional procedures, workers protect part of their body with personal shielding. In these situations, it is recommended to wear two personal dosemeters. A combination of the results of both dosemeters is used for a better estimate of the effective dose, while the dosemeter above the protective garment can help to assess the equivalent dose of the lens of the eye.
\end{abstract}

When a personal dosemeter is worn above the protective apron the detected radiation scattered field changes this study analyses the changes in the response of 7 passive and 8 active personal dosemeters when they are placed above a lead or lead-equivalent garment for S-Cs and X-ray diagnostics qualities. Monte Carlo simulations are used to support the experimental results.

It is found that for passive dosemeters, the influence on the dosemeter's response of the lead or lead equivalent layer was within the range $15-38 \%$ for the X-rays qualities. This effect is smaller, of the order of $10 \%$, when lead-free garments are used and much smaller, within $1 \%$ $10 \%$ for most of the APDs used in the study.

From these results it is concluded that when comparing passive and active dosemeters' measurements worn above a protection in interventional radiology, a difference of $20 \%-40 \%$ is expected. The effect is small when deriving the effective dose from double dosimetry algorithms but, that it can be of major importance in workplaces where eye lens monitoring is based on the use of the dosemeter worn above the protections.

\section{Introduction}

Dose monitoring of workers exposed to external ionizing radiation is usually performed by measuring the personal dose equivalent, at depth of 10 and $0.07 \mathrm{~mm}, H_{\mathrm{p}}(10)$ and $H_{\mathrm{p}}(0.07)$, with a whole body dosemeter situated on a point of the body (ICRU 1992; ICRP, 1997, ICRP 2007). In homogeneous fields, $H_{\mathrm{p}}(10)$ is a good estimate of the protection quantity effective dose, $E$, and the value of $H_{\mathrm{p}}(10)$ can be compared to the relevant dose limits for $E$. However, when workers wear protection garments, such as lead aprons or thyroid collars, the radiation field is no longer homogeneous and thus $H_{\mathrm{p}}(10)$ and $H_{\mathrm{p}}(0.07)$ do not provide a good estimate of the effective dose, $E$, and personal dosimetry is more challenging.

This is the situation in fluoroscopy guided interventional procedures where staff works in close proximity to the radiation source (X-ray tube and scattered radiation from patients) and protect part of their body with personal shielding. In this situation the ICRP recommends the use of two dosemeters, one above the protection and the other one below the protection (ICRP 2001). The determination of $E$ using an algorithm that combines the reading of the two dosemeters is known as "double-dosimetry" (Clerinx et al. 2008). By applying such double dosimetry, a better estimate of $E$ can be obtained than with just one dosemeter above or below the lead apron. Indeed, one dosemeter under the protective apron will underestimate $\mathrm{E}$, while one dosemeter above will significantly overestimate $\mathrm{E}$. 
Although double-dosimetry has been used for more than 20 years, its use is still not common practice in many countries (Bartlett et al. 2000; Carinou et al. 2018). Besides, there is no consensus about the most appropriate algorithm for workers in interventional radiology. Jarvinen et al. published a detailed literature review about available double-dosimetry algorithms and they concluded that there is not just one algorithm which is optimum for all procedures (Jarvinen et al. 2008a; 2008b). However, they also recommended the use of two dosemeters rather than a single dosemeter.

The interest in double-dosimetry and in particular in the use of a whole body dosemeter situated on an unprotected part of the body (above the thyroid collar or above the lead apron) has increased due to the recommendation of the ICRP, the IAEA and the European Commission (EC) to reduce the annual eye lens dose limit for exposed workers to $20 \mathrm{mSv}$ (ICRP 2012; IAEA 2014; EC 2014). This new value has launched a great interest in the eye lens monitoring especially for workplaces where the eyes are particularly close to the radiation emitter, such as in interventional radiology. An adequate system for monitoring shall be set up for workers liable to receive an exposure greater than an equivalent dose of $15 \mathrm{mSv}$ per year for the lens of the eye according to the European Directive 2013/59 (EC 2014). In addition, ISO 15382 recommends monitoring of the lens of the eye for workers if there is a reasonable probability to receive a dose in a single year greater than $15 \mathrm{mSv}$ or in consecutive years greater than $6 \mathrm{mSv}$ per year (ISO 2015).

The most accurate method for monitoring the equivalent dose to the lens of the eye, $H_{\text {lens }}$, is to measure the personal dose equivalent at $3 \mathrm{~mm}$ depth, $H_{\mathrm{p}}(3)$, with a dosemeter worn as close as possible to the eye and calibrated on a phantom representative of the head (ICRU 1992; Carinou et al. 2015). However, in practice, wearing the dosemeter close to the eye is not very comfortable and many users prefer to estimate $H_{\mathrm{p}}(3)$ through $H_{\mathrm{p}}(10)$ or $H_{\mathrm{p}}(0,07)$ measured with dosemeters worn above the protection (IAEA 2013; Broughton et al. 2013; Carinou et al. 2014). Therefore, at present, the use of double dosimetry is recommended both for a better estimate of $E$ and of $H_{\text {lens }}$ when part of the body is protected.

A personal dosemeter has to be designed to measure the quantity $H_{\mathrm{p}}(d)$. Type tests requirements can be found in IEC62387 for passive dosemeters (IEC 2012), and in IEC61526 for active dosemeters (IEC 2010). $H_{\mathrm{p}}(d)$ is defined in a point on the body, thus inherently including the radiation backscattered by the body (ICRU 1992). When such dosemeter is worn above the lead apron, this changes its response and will no longer be measuring the $H_{\mathrm{p}}(d)$. This issue was partially analysed for LiF personal dosemeters by Damet et al (2011), Saldariaga Vargas et al. (2018) and Quintero-Quintero et al. (2018).

Within this framework, the goal of this study is to analyse the changes in the response of, both passive and active, personal dosemeters when they are placed above a lead or lead-equivalent garment. Standard calibration set-ups are used in combination with lead or lead-equivalent absorbers. Monte Carlo simulations are used to support the experimental results.

\section{Material and methods}

\subsection{Types of dosemeters}

Seven types of passive dosemeters from seven accredited external personal dosimetry services (PDSs) including the most common types of passive detectors were selected for the study: films, optically stimulated luminescent dosemeters (OSL), radiophotoluminiscent dosemeters (RPL) and thermoluminiscent dosemeters (TLD). Table 1 summarises the characteristics of the selected systems. All dosemeters provided both measurements of $H_{\mathrm{p}}(10)$ and $H_{\mathrm{p}}(0.07)$, but only $H_{\mathrm{p}}(10)$ data will be discussed in this study. 
Table 1. Characteristics of the tested passive dosemeters

\begin{tabular}{|c|c|c|c|c|}
\hline Technology & Manufacturer & $\begin{array}{l}\text { Sensible } \\
\text { Material } \\
\end{array}$ & Holder & $\begin{array}{c}\begin{array}{c}\text { Dosimetry } \\
\text { service }\end{array} \\
\end{array}$ \\
\hline Film & Foma Bohemia & DF10+DF2 & 2 films and 4 & NIOM - Poland \\
\hline OSL & $\begin{array}{l}\text { Dosimetrics } \\
\text { GmbH }\end{array}$ & $\mathrm{BeO}$ & $\begin{array}{l}2 \text { detectors and } \\
2 \text { filters }\end{array}$ & HMGU-Germany \\
\hline OSL & Landauer Inlight & $\mathrm{Al}_{2} \mathrm{O}_{3}: \mathrm{C}$ & $\begin{array}{l}4 \text { detectors and } \\
4 \text { filters }\end{array}$ & $\begin{array}{l}\text { SCK•CEN- } \\
\text { Belgium }\end{array}$ \\
\hline RPL & $\begin{array}{c}\text { Chiyoda } \\
\text { Technol Corp. }\end{array}$ & $\begin{array}{l}\text { Phosphate } \\
\text { glass, Ag } \\
\text { dopped }\end{array}$ & $\begin{array}{l}1 \text { detector and } 5 \\
\text { filters }\end{array}$ & IRSN-France \\
\hline TLD & $\begin{array}{l}\text { Harshaw - } \\
\text { TLD-100 }\end{array}$ & $\mathrm{LiF}: \mathrm{Mg}, \mathrm{Ti}$ & $\begin{array}{l}2 \text { detectors and } \\
2 \text { filters }\end{array}$ & RBI-Croatia \\
\hline TLD & $\begin{array}{l}\text { Panasonic - } \\
\text { UD-802 }\end{array}$ & $\begin{array}{l}\mathrm{Li}_{2} \mathrm{~B}_{4} \mathrm{O}_{7} \\
\mathrm{CaSO}_{4}\end{array}$ & $\begin{array}{l}4 \text { detectors and } \\
4 \text { filters }\end{array}$ & $\begin{array}{l}\text { Dosilab- } \\
\text { Switzerland }\end{array}$ \\
\hline TLD & Rados - MTS-N & LiF:Mg,Ti & $\begin{array}{c}2 \text { detectors and } \\
2 \text { filters }\end{array}$ & EEAE-Greece \\
\hline
\end{tabular}

PDSs were requested to prepare 12 dosemeters and to measure them according to their usual procedure. All the data were treated confidentially using an identification code assigned to each type of dosemeter.

Eight types of active personal dosemeters (APDs), frequently used in Europe and with a known satisfactory energy response for photon radiation in the energy range of 30 to $100 \mathrm{keV}$ were also selected for the study. Table 2 shows the list and main characteristics of the tested APDs; all of them were based on semiconductors for the detection of radiation. The last column in Table 2 indicates the number of units per type of each APD used in the study.

Table 2. Characteristics of the tested active personal dosemeters (APDs)

\begin{tabular}{ccccc}
\hline Manufacturer & Type & Energy range & Dose rate range & $\begin{array}{c}\text { Number of } \\
\text { units }\end{array}$ \\
\hline Atomtex & AT3509C & $15 \mathrm{keV}-10 \mathrm{MeV}$ & $100 \mathrm{nSv} / \mathrm{h}-5 \mathrm{~Sv} / \mathrm{h}$ & 2 \\
Dosilab & EDM III & $20 \mathrm{keV}-6 \mathrm{MeV}$ & $500 \mathrm{nSv} / \mathrm{h}-1 \mathrm{~Sv} / \mathrm{h}$ & 3 \\
Mirion Technologies & DMC 2000 & $20 \mathrm{keV}-7 \mathrm{MeV}$ & $10 \mu \mathrm{Sv} / \mathrm{h}-10 \mathrm{~Sv} / \mathrm{h}$ & 3 \\
Mirion Technologies & DMC 3000 & $16 \mathrm{keV}-7 \mathrm{MeV}$ & $10 \mu \mathrm{Sv} / \mathrm{h}-10 \mathrm{~Sv} / \mathrm{h}$ & 3 \\
Polimaster & PM1610A & $20 \mathrm{keV}-10 \mathrm{MeV}$ & $10 \mathrm{nSv} / \mathrm{h}-12 \mathrm{~Sv} / \mathrm{h}$ & 1 \\
Polimaster & PM1621A & $10 \mathrm{keV}-20 \mathrm{MeV}$ & $10 \mathrm{nSv} / \mathrm{h}-200 \mathrm{mSv} / \mathrm{h}$ & 2 \\
RaySafe & RaySafe i2 & $33 \mathrm{keV}-101 \mathrm{keV}$ & $40 \mu \mathrm{Sv} / \mathrm{h}-300 \mathrm{mSv} / \mathrm{h}$ & 4 \\
Thermo Fisher & EPD Mk2 & $16 \mathrm{keV}-7 \mathrm{MeV}$ & $50 \mathrm{nSv} / \mathrm{h}-4 \mathrm{~Sv} / \mathrm{h}$ & 3 \\
Scientific & & & &
\end{tabular}




\subsection{Irradiation set-up}

Irradiations were carried out at UPC (Spain), NIOM (Poland), KIT (Germany) and EEAE (Greece) secondary standard accredited calibration laboratories. Dosemeters were irradiated on an ISO slab phantom following ISO 4037-3 recommendations (ISO 1996). The radiation qualities used in the irradiations were: the IEC 61267 standard Radiation Qualities in Radiation beams emerging from the X-ray source Assembly (referred to as RQR series)(IEC 2005) for an X-ray tube voltage of $70 \mathrm{kV}$ (RQR 5) and $120 \mathrm{kV}$ (RQR 9) and the ISO 4037-1 standard gamma quality corresponding to ${ }^{137} \mathrm{Cs}$ (referred to as S-Cs) (ISO 1992) were selected. The reference personal dose equivalent $H_{\mathrm{p}}(10)$ was determined using the conversion coefficients from air kerma to $H_{\mathrm{p}}(10), h_{\mathrm{pK}}(10, \mathrm{E})_{\text {slab, }}$, shown in Table 3 . For S-Cs, the coefficient indicated in ISO 4037-3 is used. For RQR qualities, conversion coefficients were calculated using Monte Carlo simulation following the procedure described in Principi et al. (2016). Table 3 summarises the main characteristics of the reference radiation qualities used in the tests, $h_{\mathrm{pK}}(10$, E) slab, and the irradiation dose range.

Table 3. Irradiation qualities, conversion coefficients and dose range

\begin{tabular}{cccccc}
\hline $\begin{array}{c}\text { Radiation } \\
\text { quality }\end{array}$ & $\begin{array}{c}\text { Radionuclide/ } \\
\text { Tube voltage }(\mathbf{k V})\end{array}$ & $\begin{array}{c}\text { HVL } \\
(\mathbf{m m} \text { Al) }\end{array}$ & $\begin{array}{c}\text { Mean energy } \\
(\mathbf{k e V})\end{array}$ & $\begin{array}{c}\boldsymbol{h}_{\mathbf{p K}}(\mathbf{1 0}, \mathbf{E}) \text { slab } \\
(\mathbf{m S v} / \mathbf{m G y})\end{array}$ & $\begin{array}{c}\text { Dose range } \\
(\mathbf{m S v})\end{array}$ \\
\hline S-Cs & ${ }^{137} \mathrm{Cs}$ & - & 662 & 1.21 & $2-5$ \\
RQR 9 & 120 & 5.00 & 56 & 1.52 & $2-5$ \\
RQR 5 & 70 & 2.41 & 38 & 1.176 & $2-5$ \\
\hline
\end{tabular}

For the passive dosemeters, for each radiation quality, two units of each dosemeter type were irradiated at the same time. Then the irradiations of two additional dosemeters were repeated placing a $0.5 \mathrm{~mm}$ lead layer between the dosemeters and the phantom. Figure 1 illustrates the set-up for two types of passive dosemeters. Once irradiated the passive dosemeters were sent to the PDSs for evaluation. The PDSs had no information about the irradiation set-up: photon radiation qualities or when the lead layer was or was not used. Two background dosemeters were included so that background and transport doses were taken into account.
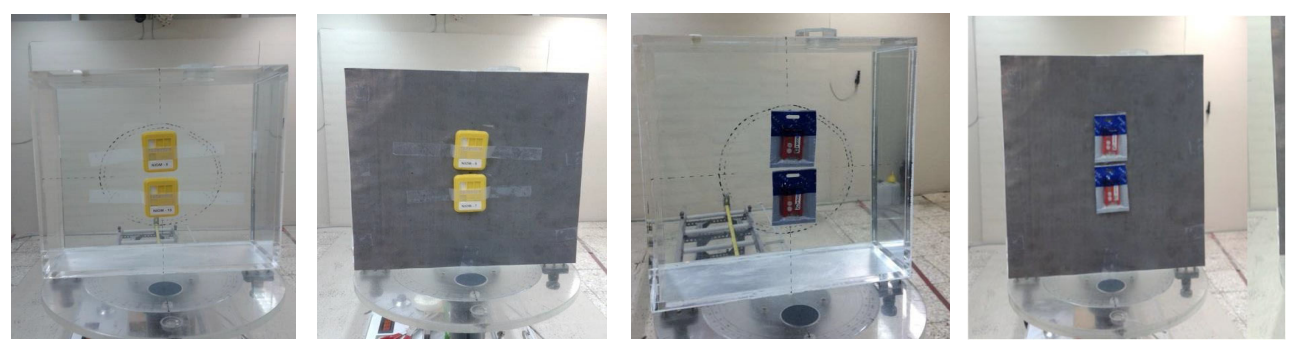

Figure 1. Example of the irradiation with and without lead layer for a film and a TLD dosemeter

For APDs, a single dosemeter was placed in the center of the phantom. The dosemeters were positioned perpendicular to the axis of the radiation beam, taking into account the manufacturers' guidelines with regard to determining the center of the active area. Irradiations as in the case of passive detectors were made on the ISO phantom without and in the presence of a $0.5 \mathrm{~mm}$ lead layer. All the available units of each type were tested and a mean reading of 3 irradiations was obtained in each case. Figure 2 illustrates the set-up for active dosemeters. 


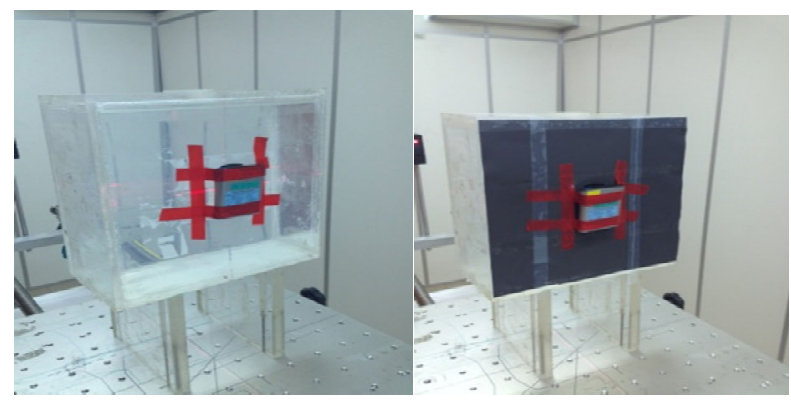

Figure 2. Example of the irradiation with and without lead layer for an APD

Regarding clinical protective garments, at the moment, lead is being replaced by either composite lead or lead-free materials with other high atomic elements. These newer aprons are categorised by manufacturers in terms of lead equivalent values. In order to investigate the response of both passive and active dosemeters in these cases, for the RADOS TLD and the Thermo Fisher Scientific MK2, the irradiations were repeated using the ISO phantom and two types of commercial aprons ( $0.5 \mathrm{~mm} \mathrm{~Pb}$ equivalent): envirolite lead-free $1110 \mathrm{LF}$ type apron manufactured by ProtecX Medical Ltd (figure 3b) and XP/N800 type apron manufactured by Agsa gomma S.R.L (figure 3c). The exact chemical composition of the aprons was not provided by the manufacturers. According to the available information, the Protec $X$ apron is composed of $75-85 \%$ heavy metal composites, not including lead, encapsulated in a vinyl resin and plasticiser matrix, and it provides an attenuation on direct field of $99.3 \%$ at $70 \mathrm{kV}$ and $97.6 \%$ at $90 \mathrm{kV}$. The Agsa gomma is made with a layer of lead rubber material embedded in cotton fabric on one side and water-proof material on the other side and it provides an attenuation of $99 \%$ at $80 \mathrm{kV}$ and $97 \%$ at $100 \mathrm{kV}$. In the following paragraphs the Protec $X$ apron will be referred as lead-free apron and the Agsa gomma as lead-composite apron.

For this second test, six Rados TLDs and three measurements of two Thermo Fisher Sc. EPD MK2 units are used for each set-up. Figure 3 illustrates the experimental set-up with real aprons used in clinical practice.
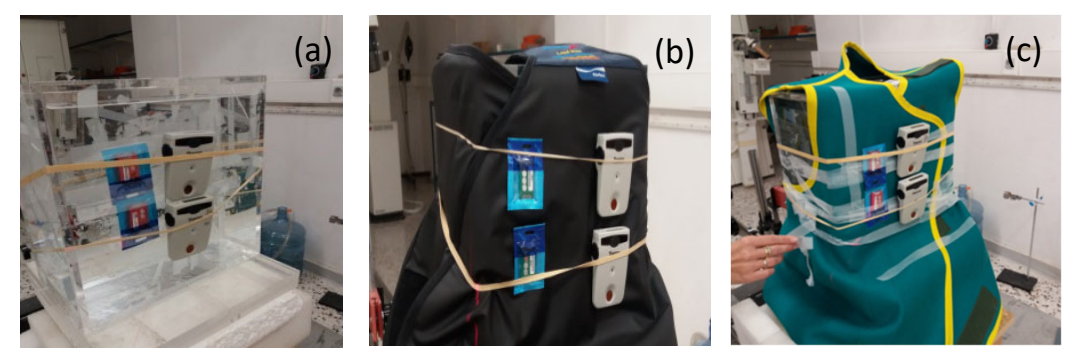

Figure 3. Irradiation set-up using the passive and active detectors on ISO slab phantom (a), with Protec X apron (b) and with Agsa gomma apron (c).

\subsection{Monte Carlo simulation}

A LiF dosemeter was simulated using the MCNPX code version 2.6.0. (Pelowitz 2005) and PENELOPE/PenEasy version 2015-05-30 (Salvat 2011; Sempau et al. 2011). The calculations aimed at having a better understanding of the influence of the lead layer in the dosemeters' response and the energy deposited at a detector situated in front of a 30x30x15 $\mathrm{cm}^{3} 4$-element ICRU slab phantom with and without lead. The energy deposition tally in PENELOPE and F6 tally in MCNPX were used for the simulations. The kerma approximation was considered for the simulations due to the photon energy range of interest (Zankl et al. 2002, Daures et al. 2010). In the present work, a total of $10^{9}$ photon histories were simulated in order to obtain 
small calculation uncertainties. This number of simulations ensured that the relative statistical uncertainty was less than $1 \%$.

The radiation source was a uniformly distributed parallel square source of $30 \mathrm{~cm} \times 30 \mathrm{~cm}$ (to ensure the coverage of the whole front face of the slab). It is positioned at $5 \mathrm{~cm}$ distance from the phantom in vacuum. The energy spectra studied were the S-Cs quality as reference energy and the IEC 61267 RQR qualities from RQR 5 to RQR 9 because they are similar to the radiation beams typically encountered in fluoroscopically guided interventional procedures. The X-ray spectra were generated using the program XCOMP5 (Nowotny and Hofer 1985) and the X-ray tube parameters of the UPC irradiation facility used in the experiments (anode angle of $18^{\circ}$ and $7 \mathrm{~mm}$ Be inherent filtration).

The TLD was simulated as a cylinder of LiF material, with diameter of $4.5 \mathrm{~mm}$ and $0.8 \mathrm{~mm}$

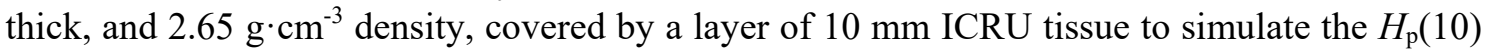
quantity. These dimensions correspond to one of the passive dosemeters tested. In order to quantify the effect of the presence of the lead beneath the TLD, simulations are repeated with a 0.5 -mm-thick lead layer between the detector and the slab phantom. Figure 4 illustrates the geometry used in the simulations, PENELOPE view mode with lead layer.

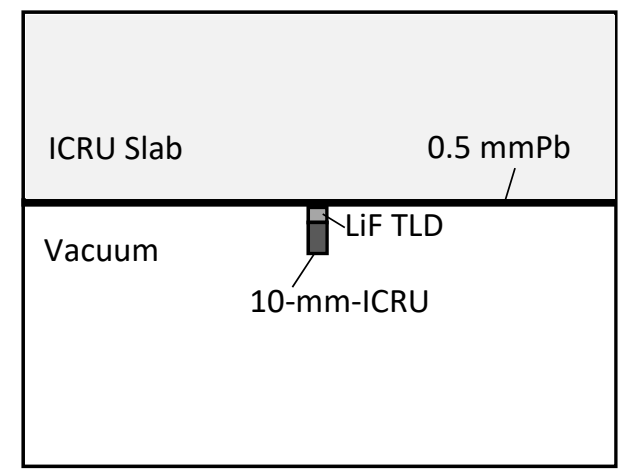

Figure 4. Geometry used in the simulations with the lead layer between the detector and the phantom.

MCNPX simulations were repeated for a lead layer of $0.25 \mathrm{~mm}$ and $0.35 \mathrm{~mm}$, in order to illustrate the validity of our study in the case of the use of thinner protection garments.

\subsection{Statistical analysis}

The statistical analysis was performed using the IBM SPSS Statistics version 25.0 software package (IBM 2017). The statistical significance of the influence of the protective garment was evaluated using an independent samples $t$-test. The significance level is set to $5 \%$.

\section{Results}

\subsection{Passive dosemeters}

Table 4 summarises the responses of the 7 PDSs. Columns 2, 3 and 4 show the response of the passive dosemeters. The response is defined as the ratio of the participant's reported value $\left(H_{\mathrm{p}}(10)_{\text {phan }}\right)$ and the corresponding reference value $\left(H_{\mathrm{p}}(10)_{\mathrm{ref}}\right)$. Columns 5,6 and 7 show the influence of the lead layer in the dosemeters' response, determined as the ratio of the dosemeter reading with $\left(H_{\mathrm{p}}(10)_{\mathrm{Pb}}\right)$ and without the $0.5-\mathrm{mm}$ lead layer $\left(H_{\mathrm{p}}(10)_{\text {phan }}\right)$. One of the services which used TLD detectors underestimated the given dose by about $60 \%-40 \%$ for X-ray qualities and about $20 \%$ for S-Cs when the dosemeter was situated above the lead apron. Their results are not included in the last columns of Table 4, because the service recognised the fact 
that their dosimetry algorithm failed to correctly identify the type of radiation field and thus significantly underestimated the dose. The last row in Table 4 indicates the number of services, $\mathrm{N}$, used in the calculations. As indicated in session 2.1, all services provided measurements of $H_{\mathrm{p}}(0.07)$ but these data are not presented here since the behavior, as regards the influence of protective materials, is analogous.

Table 4. Summary of the response of $N$ dosimetry systems: mean, standard deviation, maximum and minimum for ${ }^{137} \mathrm{Cs}$, RQR 9 and RQR 5. Comparison with the reference value, $\mathrm{H}_{\mathrm{p}}(10)_{\text {ref }}$ and influence of the presence of a $0.5 \mathrm{~mm} \mathrm{~Pb}$ layer.

\begin{tabular}{ccccccc}
\hline & \multicolumn{3}{c}{$\boldsymbol{H}_{\mathbf{p}}(\mathbf{1 0})_{\text {phan }} / \boldsymbol{H}_{\mathbf{p}}(\mathbf{1 0})_{\text {ref }}$} & \multicolumn{3}{c}{$\boldsymbol{H}_{\mathbf{p}}(\mathbf{1 0}) \mathbf{P b} / \boldsymbol{H}_{\mathbf{p}}(\mathbf{1 0})_{\text {phan }}$} \\
\hline & S-Cs & RQR 9 & RQR 5 & S-Cs & RQR 9 & RQR 5 \\
\hline Mean & 1.00 & 0.97 & 1.03 & 0.95 & 0.71 & 0.76 \\
Sd & 0.11 & 0.12 & 0.15 & 0.04 & 0.05 & 0.04 \\
Max & 1.15 & 1.13 & 1.24 & 1.02 & 0.75 & 0.81 \\
Min & 0.85 & 0.79 & 0.85 & 0.91 & 0.62 & 0.70 \\
N & 7 & 7 & 7 & 6 & 6 & 6 \\
\hline
\end{tabular}

Table 5 shows the performance of the RADOS TLD when placed above a $0.5-\mathrm{mm}$ lead layer and above the two types of $0.5-\mathrm{mm}$ lead equivalent protective aprons. The mean value and standard deviation of the $H_{\mathrm{p}}(10)$ ratio with and without absorber, and the number of measurements for each set-up, $n$, are given in Table 5.

Table 5. Ratio of the RADOS TLD detector measurements when placed in front of a $0.5 \mathrm{~mm}$ lead layer and in front of two types of $0.5-\mathrm{mm}$ lead equivalent protective aprons and when placed directly on the ISO slab phantom (mean value and standard deviation)

\begin{tabular}{|c|c|c|c|c|c|c|c|}
\hline RADOS TLD & $n$ & \multicolumn{2}{|c|}{ S-Cs } & \multicolumn{2}{|c|}{ RQR 9} & \multicolumn{2}{|c|}{ RQR 5} \\
\hline$H_{\mathrm{p}}(10)_{\mathrm{Pb}} / H_{\mathrm{p}}(10)_{\mathrm{phan}}$ & 2 & 0.96 & \pm 0.01 & 0.71 & \pm 0.01 & 0.74 & \pm 0.01 \\
\hline$H_{\mathrm{p}}(10)_{\mathrm{Pb}-\text {-ree }} / H_{\mathrm{p}}(10)_{\mathrm{phan}}$ & 6 & 0.99 & \pm 0.01 & 0.90 & \pm 0.02 & 0.96 & \pm 0.02 \\
\hline$H_{\mathrm{p}}(10)_{\mathrm{Pb}-\mathrm{comp}} / H_{\mathrm{p}}(10)_{\mathrm{phan}}$ & 6 & 0.98 & \pm 0.02 & 0.75 & \pm 0.01 & 0.79 & \pm 0.01 \\
\hline
\end{tabular}

\subsection{Active dosemeters}

Table 6 summarises the responses of the 8 APDs for the $H_{\mathrm{p}}(10)$ quantity. Three of the APDs also measure $H_{\mathrm{p}}(0.07)$ but these data are not presented here since the behavior, as regards the influence of protective materials, is analogous. The mean and standard deviation of the response has been calculated for all ratios separately for each type of dosemeter.

Table 6. Response of the 8 tested APDs for $H_{\mathrm{p}}(10)$ for S-Cs, RQR 5 and RQR 9 (mean value and standard deviation)

\begin{tabular}{cccccccccc}
\cline { 3 - 9 } & & & \multicolumn{5}{c}{$\boldsymbol{H}_{\mathbf{p}}(\mathbf{1 0})_{\mathbf{A P D}} / \boldsymbol{H}_{\mathbf{p}}(\mathbf{1 0})_{\text {ref }}$} \\
\hline Manufacturer & Type & \# units & \multicolumn{2}{c}{ S-Cs } & \multicolumn{2}{c}{ RQR 9 } & \multicolumn{2}{c}{ RQR 5 } \\
\hline Atomex & AT3509C & 2 & 1.12 & \pm 0.02 & 1.48 & \pm 0.04 & 0.80 & \pm 0.02 \\
Dosilab & EDM-III & 3 & 1.03 & \pm 0.01 & 1.00 & \pm 0.01 & 0.87 & \pm 0.02 \\
Mirion Technologies & DMC2000XB & 3 & 1.03 & \pm 0.01 & 1.11 & \pm 0.05 & 1.07 & \pm 0.04 \\
Mirion Technologies & DMC3000 & 3 & 1.01 & \pm 0.01 & 1.11 & \pm 0.01 & 1.14 & \pm 0.01 \\
Polimaster & PM1610A & 1 & 0.96 & \pm 0.01 & 1.02 & \pm 0.01 & 0.88 & \pm 0.01 \\
Polimaster & PM1621A & 2 & 0.97 & \pm 0.01 & 1.26 & \pm 0.07 & 1.13 & \pm 0.08 \\
RaySafei2 & RaySafei2 & 4 & 0.44 & \pm 0.03 & 1.04 & \pm 0.10 & 0.94 & \pm 0.10
\end{tabular}


Table 7 presents the ratio of the APDs' measurements when irradiated above the $0.5 \mathrm{~mm}$ lead layer $H_{\mathrm{p}}(10)_{\mathrm{Pb}}$ and on the phantom, $H_{\mathrm{p}}(10)_{\text {phan }}$, for each type of APD. Table 8 summarises the data from Tables 6 and 7, considering the 8 APDs together.

Table 7. Ratio of $H_{\mathrm{p}}(10)$ measured over the protection $H_{\mathrm{p}}(10)_{\mathrm{Pb}}$ and on the phantom for S-Cs; RQR 5 and RQR 9 (mean value and standard deviation).

\begin{tabular}{cccccccccc}
\cline { 3 - 9 } & & & \multicolumn{5}{c}{$\boldsymbol{H}_{\mathbf{p}}(\mathbf{1 0}) \mathbf{p b} / \boldsymbol{H}_{\mathbf{p}}(\mathbf{1 0})$ phan } \\
\hline Manufacturer & Type & \# units & \multicolumn{2}{c}{ Cs-137 } & \multicolumn{2}{c}{$\mathbf{R Q R ~ 9}$} & RQR 5 \\
\hline Atomtex & AT3509C & 2 & 0.95 & \pm 0.03 & 0.89 & \pm 0.02 & 0.94 & \pm 0.01 \\
Dosilab & EDM-III & 3 & 1.05 & \pm 0.02 & 0.98 & \pm 0.02 & 0.99 & \pm 0.01 \\
Mirion & DMC2000XB & 4 & 0.94 & \pm 0.02 & 0.91 & \pm 0.05 & 0.96 & \pm 0.06 \\
Mirion & DMC3000 & 3 & 0.95 & \pm 0.01 & 0.94 & \pm 0.01 & 0.99 & \pm 0.01 \\
Polimaster & PM1610A & 1 & 0.95 & \pm 0.00 & 0.92 & \pm 0.02 & 0.99 & \pm 0.01 \\
Polimaster & PM1621A & 2 & 0.95 & \pm 0.03 & 0.97 & \pm 0.03 & 0.97 & \pm 0.02 \\
RaySafei2 & RaySafei2 & 4 & 0.98 & \pm 0.02 & 0.78 & \pm 0.04 & 0.88 & \pm 0.05 \\
Thermo Fisher Sc. & MK2 & 3 & 0.95 & \pm 0.01 & 0.98 & \pm 0.01 & 0.99 & \pm 0.01 \\
\hline
\end{tabular}

Table 8. Summary of the response of $N$ APDs: mean, standard deviation, maximum and minimum for S-Cs, RQR 9 and RQR 5. Comparison with the reference value, $H_{\mathrm{p}}(10)_{\text {ref, }}$, and influence of the presence of a $0.5 \mathrm{~mm} \mathrm{~Pb}$ layer.

\begin{tabular}{ccccccc}
\hline & \multicolumn{3}{c}{$\boldsymbol{H}_{\mathrm{p}}(\mathbf{1 0})_{\mathrm{phan}} / \boldsymbol{H}_{\mathrm{p}}(\mathbf{1 0})_{\text {ref }}$} & \multicolumn{3}{c}{$\boldsymbol{H}_{\mathrm{p}}(\mathbf{1 0}) \mathrm{Pb} / \boldsymbol{H}_{\mathrm{p}}(\mathbf{1 0})_{\text {phan }}$} \\
\hline & S-Cs & RQR 9 & RQR 5 & S-Cs & RQR 9 & RQR 5 \\
\hline Mean & 1.02 & 1.13 & 0.98 & 0.97 & 0.92 & 0.96 \\
Sd & 0.05 & 0.17 & 0.13 & 0.04 & 0.07 & 0.04 \\
Max & 1.12 & 1.48 & 1.14 & 1.05 & 0.98 & 0.99 \\
Min & 0.96 & 0.98 & 0.8 & 0.94 & 0.78 & 0.88 \\
$N$ & $7 *$ & 8 & 8 & 8 & 8 & 8 \\
\hline
\end{tabular}

* For S-Cs the Raysafe is not included in this analysis because it is outside the working range indicated by the manufacturer.

Table 9 shows the performance of the Thermo Fisher Sc. EPD Mk2 when placed above a 0.5$\mathrm{mm}$ lead layer and the two types of $0.5-\mathrm{mm}$ lead equivalent protective aprons. The mean value and standard deviation of the $H_{\mathrm{p}}(10)$ ratio with and without absorber, and the number of measurements, $n$, for each set-up are given in Table 9.

Table 9. Ratio of the Thermo Fisher Sc. APD when placed in front of a $0.5 \mathrm{~mm}$ lead layer or in front of two lead-free aprons and when placed directly on the ISO slab phantom (mean value and standard deviation)

\begin{tabular}{|c|c|c|c|c|c|c|c|}
\hline Thermo Fisher Sc. EPD Mk2 & $n$ & \multicolumn{2}{|c|}{ S-Cs } & \multicolumn{2}{|c|}{ RQR 9} & \multicolumn{2}{|c|}{ RQR 5} \\
\hline$H_{\mathrm{p}}(10)_{\mathrm{pb}} / H_{\mathrm{p}}(10)_{\mathrm{phan}}$ & 9 & 0.95 & \pm 0.01 & 0.98 & \pm 0.01 & 0.99 & \pm 0.01 \\
\hline$H_{\mathrm{p}}(10)_{\mathrm{Pb}-\text {-free }} / H_{\mathrm{p}}(10)_{\mathrm{phan}}$ & 6 & 0.97 & \pm 0.04 & 0.98 & \pm 0.01 & 0.99 & \pm 0.03 \\
\hline$H_{\mathrm{p}}(10)_{\mathrm{Pb}-\text { comp }} / H_{\mathrm{p}}(10)_{\mathrm{phan}}$ & 6 & 0.98 & \pm 0.01 & 0.99 & \pm 0.01 & 0.99 & \pm 0.01 \\
\hline
\end{tabular}




\subsection{Monte Carlo simulation}

Table 10 summarises the Monte Carlo simulation results. It shows the ratio of $H_{\mathrm{p}}(10)$ above 0.5 mm lead layer and $H_{\mathrm{p}}(10)$ on the phantom, $H_{\mathrm{p}}(10)_{\mathrm{Pb}} / H_{\mathrm{p}}(10)_{\mathrm{phan}}$, obtained as the average of the ratios from PENELOPE and MCNPX. The associated uncertainty of the mean of the ratios is calculated as the difference between the two Monte Carlo results and divided by the mean $H_{\mathrm{p}}(10)_{\mathrm{Pb}} / H_{\mathrm{p}}(10)_{\mathrm{phan}}$.

Table 10. Response of a simulated $\mathrm{LiF} \mathrm{TL}$ detector when placed above a $0.5 \mathrm{~mm} \mathrm{~Pb}$ layer $\left(H_{\mathrm{p}}(10)_{\mathrm{Pb}}\right)$ or in front of an ICRU slab phantom.

\begin{tabular}{ccccccc}
\hline & S-Cs & RQR 9 & RQR 8 & RQR 7 & RQR 6 & RQR 5 \\
\hline High voltage (kV) & & 120 & 100 & 90 & 80 & 70 \\
Mean energy (keV) & 662 & 56 & 48 & 44 & 41 & 38 \\
$\boldsymbol{H}_{\mathrm{p}}(\mathbf{1 0}) \mathbf{P b} / \boldsymbol{H}_{\mathrm{p}}(\mathbf{1 0})$ phan & 0.94 & 0.73 & 0.73 & 0.74 & 0.76 & 0.79 \\
$\begin{array}{c}\text { Uncertainty of the } \\
\text { mean (\%) (k=1) }\end{array}$ & 3.7 & 2.1 & 1.7 & 1.1 & 0.4 & 0.2 \\
\hline
\end{tabular}

Calculations for thicknesses of $0.35 \mathrm{~mm}$ and $0.25 \mathrm{~mm}$ showed that the lead thickness influence is less than $0.5 \%$ in all RQR qualities. In the case of S-Cs there is a variation of $1 \%$ and $1.7 \%$, respectively.

\section{Discussion}

Table 4 shows that all 7 selected passive dosimetry services present a good accuracy and reproducibility for all tested radiation qualities, consistent within 2 standard deviations. However, when situated in front of a lead layer, one of the services was not able to correctly measure the dose, which highlights that some algorithms might have difficulties in this situation. For the rest of the services, it was found that the influence of the lead layer was small for ${ }^{137} \mathrm{Cs}$, in average $5 \%$ with a maximum underestimation of $9 \%$, whereas, for the X-ray qualities, all systems underestimated the dose within the range $19 \%-38 \%$, in average $25 \%$. The largest underestimate was obtained for RQR 9. Similar behavior was found, independently from the type of radiation sensor used (TLD, OSL, RPL or film). An independent samples t-test was conducted to confirm the statistically significance of the observed behavior. It was confirmed that the difference is not significant for S-Cs $(\mathrm{t}(10)=0.682, \mathrm{p}=0.511)$, but it is for RQR 9 $(\mathrm{t}(10)=4.397, \mathrm{p}=0.001)$ and RQR $5(\mathrm{t}(10)=3.369, \mathrm{p}=0.007)$.

Monte Carlo simulations confirm these results showing an underestimate of $21 \%$ for RQR 5 and of $27 \%$ for RQR 9. There is also good agreement with the findings of Damet et al (2011) and Saldariaga Vargas (2018). Damet et al (2011) concluded that the personal dose equivalent measured with a Radpro dosemeter with TLD-100 detectors was underestimated by $20 \%-40 \%$ for X-ray beam qualities used in radiology when dosemeters were placed over the personal protection. Likewise, Saldariaga Vargas et al. (2018) found out, by means of Monte Carlo calculations, that a $\mathrm{LiF}$ personal passive dosemeter would underestimate the dose by $17 \%$ to $37 \%$ in this energy range.

In the case of the tested protective garments (Table 5), it was observed that, for the lead composite apron (figure 3c), the TL dosemeter measurements presented no significant differences compared with the response in front of the $0.5 \mathrm{~mm} \mathrm{~Pb}$ layer: no changes for S-Cs $(\mathrm{p}=0.145)$ and a reduction between $20 \%-25 \%$ for the X-ray qualities $(\mathrm{p}<0.001$ for RQR 5 and 
RQR 9). For the lead-free garment (figure 3b), the influence was much smaller, within $10 \%$ for both X-ray qualities, as it was described by Damet et al. (2011). However, an independent samples t-test shows a statistically significant difference between the mean value of the response with and without garment for X-rays.

The tested APDs (Table 6) presented responses within 20\%, except for the Raysafei2 that underestimate the dose by $56 \%$ for S-Cs and the Atomex AT3509C and the Polimaster PM1621A that overestimate the dose by $26 \%$ and $48 \%$, respectively, for the RQR 9 quality. The influence of the lead layer in the APDs' response is much smaller than for the passive dosemeters. For most APDs the ratio of the response with or without lead layer is within $10 \%$. The only exceptions are found for the RaySafei2 and for the Atomex AT3509C. For the RaySafei2, the influence of the lead apron layer is of the same order than for passive dosemeters, with a reduction of the measurement of $12 \%$ and $23 \%$, for RQR 5 and RQR 9, respectively. The Atomex AT3509C reduced its response around 11\% for RQR 9. However, as this dosemeter overestimated the dose for this quality, it can be considered that the measurement over the apron is closer to the reference value.

Table 9 shows that the performance of the Thermo Fisher Sc. MK2 when placed above a 0.5 $\mathrm{mm}$ lead layer or in front of the two commercial lead equivalent aprons does not change compared with when there is no protection. The differences are within $5 \%$ and within the standard deviation of the measurement. It may be inferred that the rest of the APDs would present analogous responses. These observations highlight the fact that APDs' measurements will not vary when they are worn above a lead-composite or a lead-free apron.

The good agreement on the dosemeters' response above a lead layer and an equivalent lead composite shows the representativeness of the presented results in practice. Moreover, the Monte Carlo results show that, in the energy range of interest, an analogous behavior is expected for lead thicknesses between $0.25 \mathrm{~mm}$ and $0.5 \mathrm{~mm}$.

As discussed earlier, at present there is not a unique recommended double dosimetry algorithm to estimate the effective dose, but, in most of them, the contribution to the effective dose of the measurement with the unprotected dosemeter is less than $10 \%$ (Jarvinen 2008a), thus the observed $20 \%-40 \%$ underestimation of the passive dosemeters will, in general, be negligible from a radiation protection point of view in the calculation of the effective dose.

On the other hand, when the over-dosemeter measurement is used to estimate the lens of the eye, the impact of the $20 \%-40 \%$ underestimation of the passive dosemeter can be of major importance since the dose limits for the eye lens could be exceeded. Several studies highlight the difficulties to correctly estimate the dose of the lens of the eye with a dosemeter that is not situated close to the eyes in a non-homogeneous radiation field (Carinou et al. 2015, Principi et al. 2015). The results of this study point out that in interventional radiology, if a protective garment with lead is used, the effect of the underestimation of the passive dosemeter should be taken into consideration. Additional studies are needed to confirm the influence of the composition of the garments. To overcome the effect of the protection garments in the passive dosemeters, Quintero-Quintero et al. (2018) propose a specific calibration procedure which could be adapted to other dosemeters.

As described in the introduction, in practice, the equivalent dose to the lens of the eye is often estimated using a whole body dosemeter calibrated in units of $H_{\mathrm{p}}(10)$ situated above the protection. However, even though such a measurement is used, the results of the eye lens monitoring should be expressed in terms of the appropriate operational quantity, $H_{\mathrm{p}}(3)$. 


\section{Conclusion}

When a dosemeter is worn above a protective apron, it is no longer measuring the quantity $H_{\mathrm{p}}(10)$ for which the dosemeter was type-tested. Part of the backscatter of the body will no longer reach the dosemeter, and the backscattered spectra changes, e.g., lead aprons give rise to characteristic X-rays of 72 and $75 \mathrm{keV}$.

Because of this, the personal dose equivalent measured with a passive dosemeter worn over a lead apron is underestimated by $20 \%-40 \%$ in typical diagnostic X-ray energies. This is not the case of active dosemeters, because they are designed so that they are less sensitive to the backscatter radiation, and as such it does not make much difference if they are worn directly on the body or on a protective apron. The Raysafei2 system is an exception in this respect.

From these results it can be concluded that when comparing passive and active dosemeters' measurements worn above a protection in interventional radiology, a difference of $20 \%-40 \%$ should be expected. Although for the moment active dosemeters are not yet much used in hospitals, this is likely to increase in the future (Sánchez et al. 2010; Clairand et al 2011; Struelens et al. 2011).

As regards the influence of the effect of the protection garment for the estimation of the effective dose with a double dosimetry algorithm, it is shown that the effect is small from a radiation protection point of view, $5 \%$ for passive dosemeters and negligible for APDs. Nevertheless, since most of these algorithms were proposed before the ICRP 103 report was published (ICRP 2007) and thus, use the old tissue weighting factors for the calculation of the effective dose, it could be a good opportunity to propose new double dosimetry algorithms that could also take into account the effect of the new types of protective garments.

The observed underestimation could however be of major importance in workplaces where eye lens monitoring is based on the use of a dosemeter worn over a lead apron or a thyroid collar. In this case, $20 \%-40 \%$ underestimation can make a significant difference. Since APDs do not present this limitation their use could be encouraged not only to increase awareness of the radiation risk and to help optimise the use of protection but also to prevent exceeding the dose limit.

\section{REFERENCES}

Bartlett, D. J., Ambrosi, P., Bordy, J. M. and Van Dijk, J. W. E. (eds). 2000. "Harmonisation and dosimetric quality assurance in individual monitoring for external radiation". Radiat. Prot. Dosim. 89 1-154.

Broughton, J., Cantone, M.C., Ginjaume, M., Shah, B., 2013. "Report of Task Group on the implications of the implementation of the ICRP recommendations for a revised dose limit to the lens of the eye". J. Radiol. Prot. 33855.868

Carinou, E., Ginjaume, M., O'Connor, U., Kopec, R. and Sans Merce, M. 2014. "Status of Eye Lens Radiation Dose Monitoring in European Hospitals." J. Radiol. Prot. 34 (4) 729-739. 
Carinou, E., Ferrari, P., Ciraj Bjelac, O., Ginjaume, M., Sans Merce, M. y O’Connor, U. 2015. "Eye lens monitoring for interventional radiology personnel: dosemeters, calibration and practical aspects of $H_{\mathrm{P}}(3)$ monitoring. A 2015 review". J. Radiol. Prot. 35(3) R17-R34.

Carinou, E., Kollaard, R., Petrovic, J., Ginjaume, M. “A European survey on the regulatory status for the estimation of the effective dose and the equivalent dose to the lens of the eye". Submited to J. Radiol. Prot. ref. JRP-101430.

Clairand I, Bordy JM, Carinou E, et al. 2011. "Use of active personal dosimeters in interventional radiology and cardiology: tests in laboratory conditions and recommendations - ORAMED project". Radiat Meas. 46 1252-1257.

Clerinx, P., Buls, N., Bosmans H. y De Mey, J. 2008. "Double-Dosimetry Algorithm for Workers in Interventional Radiology". Radiat Prot Dosim. 129 (1-3) 321-327.

Damet, J., Bailat, C., Bize, P., Buchillier, Th., Tosic, M., Verdun, F. R. and Baechler, S. 2011. "Individual monitoring of medical staff working in interventional radiology in Switzerland using double dosimetry”. Radiat. Meas. 46 1839-1842.

Daures, J., Gouriou, J., Bordy, J.M. 2011. "Monte Carlo determination of the conversion coefficients $H_{\mathrm{p}}(3) / K_{\mathrm{a}}$ in a right cylinder phantom with 'PENELOPE' code. Comparison with 'MCNP' simulations". Radiat.Prot. Dosim.144 (1-4) 37-42.

EC 2014. "Council Directive 2013/59/Euratom of 5 December 2013 Laying down Basic Safety Standards for Protection against the Dangers Arising from Exposure to Ionising Radiation, and Repealing Directives 89/618/Euratom, 90/641/Euratom, 96/29/Euratom, 97/43/Euratom and 2003/122/Euratom".

IAEA. 2014. "Radiation Protection and Safety of Radiation Sources: International Basic Safety Standards. General Safety Requirements Part 3". No. GSR Part 3. Vienna.

IAEA. 2013. IAEA Tec Doc-1731. "Implications for Occupational Radiation Protection of the New Dose Limit for the Lens of the Eye". ISSN10114289. Vienna.

IBM. 2017. IBM SPSS Statistics 25.0

ICRP, 1997. ICRP Publication 75. "General Principles for the Radiation Protection of Workers”. Ann. ICRP 27 (1).

ICRP. 2001. ICRP Publication 85. "Avoidance of Radiation Injuries from Medical Interventional Procedures". Ann. ICRP 30 (2).

ICRP, 2007. ICRP Publication 103. "The 2007 Recommendations of the International Commission on Radiological 1056 Protection”. Ann. ICRP 37 (2-4).

ICRP, 2012. ICRP Publication 118. "ICRP Statement on Tissue Reactions / Early and Late Effects of Radiation in Normal Tissues and Organs - Threshold Doses for Tissue Reactions in a Radiation Protection Context". Ann. ICRP 41(1/2).

ICRU. 1992. Report 47. "Measurement of Dose Equivalents from External Photon and Electron Radiations.". ICRU Publications, Bethesda.

IEC. 2005. IEC 61267 Ed.2. "Medical diagnostic X-ray equipment-radiation conditions for use in the determination of characteristics". IEC, Geneva. 
IEC. 2010. IEC 61526 Ed.3. "Radiation protection instrumentation - Measurement of personal dose equivalents $\mathrm{Hp}(10)$ and $\mathrm{Hp}(0,07)$ for $\mathrm{X}$, gamma, neutron and beta radiations - Direct reading personal dose equivalent meters". IEC, Geneva.

IEC. 2012. IEC 62387 Ed.1. "Radiation Protection Instrumentation - Passive integrating dosimetry systems for personal and environmental monitoring of photon and beta radiation." IEC, Geneva.

ISO. 1996. ISO 4037-1. " $\mathrm{X}$ and gamma reference radiation for calibrating dosemeters and doserate meters and for determining their response as a function of photon energy - Part 1 : radiation characteristics and production methods". ISO, Geneva.

ISO. 1999. ISO 4037-3. "X and gamma reference radiation for calibrating dosemeters and doserate meters and for determining their response as a function of photon energy - Part 3: calibration of area and personal dosemeters and the measurement of their response as a function of energy and angle of incidence". ISO, Geneva.

ISO. 2015. ISO 15382. "Radiological protection - Procedures for monitoring the dose to the lens of the eye, the skin and the extremities". ISO, Geneva.

Järvinen, H., Buls, N., Clerinx, P., Jansen, J., Miljanic, S., Nikodemová, D., Ranogajec-Komor, M. y D'Errico, F. 2008a. "Overview of Double Dosimetry Procedures for the Determination of the Effective Dose to Interventional Radiology Staff'. Radiat. Prot. Dosim. 129, 333-339.

Järvinen, H., Buls, N., Clerinx, P., Miljanić, S., Nikodemová, D., Ranogajec-komor, M., Struelens, L. y D'Errico, F. 2008b. "Comparison of Double Dosimetry Algorithms for Estimating the Effective Dose in Occupational Dosimetry of Interventional Radiology Staff'. Radiat. Prot. Dosim.. 131 (1), 80-86 (2008b).

Nowotny, R., \& Hofer, A. (1985). XCOMP5, Program for calculating diagnostic x-ray spectra. RoeFo, Fortschr. Geb.Roentgenstr. Nuklearmed. 142, pp. 685-689.

Pelowitz D.B. MCNPX Users Manual, Version 2.6.0. 2005. Los Alamos National Laboratory Report. LA-CP-05-0369.

Principi S., Guardiola C., Duch MA., Ginjaume M. 2016 "Air kerma to $H_{\mathrm{p}}(3)$ conversion coefficients for IEC $61267 \mathrm{RQR}$ X-ray radiation qualities: application to dose monitoring of the lens of the eye in medical diagnostics". Radiat Prot Dosim. 170(1-4) 45-48.

Principi, S., Ginjaume, M., Duch, M.A., Sánchez, R., Fernández, J., Vañó, E. 2015. “Infuence of dosemeter position for the assessment of eye lens dose during interventional cardiology". Radiat. Prot. Dosim. 164(1-2) 79-83.

Quintero-Quintero A., G Patiño-Camargo G., Á Soriano A.,J D Palma JD, Vilar-Palop J, Pujades MC, Llorca-Domaica N, Ballester F., J Vijande J. and Candela-Juan C. 2018. "Calibration of a thermoluminescent dosimeter worn over lead aprons in fluoroscopy guided procedures". J. Radiol. Prot. 38 549-564.

Saldariaga Vargas C., Struelens L. and Vanhavere F. 2018. "The challenges in the estimation of the effective dose when wearing radioprotective garments". Radiat. Prot. Dosim. 178 (1) $101-111$. 
Salvat F., Fernandez-Varea J.M. and Sempau J. 2011. "PENELOPE 2011: A Code System for MonteCarlo Simulation of Electron and Photon Transport". Workshop Proceedings Barcelona, Spain, 4-7 July 2011, Data Bank NEA/NSC/Doc (2011)3.

Sanchez, R., Vano, E., Fernandez, J. M. and Gallego, J. J. 2010. "Staff radiation doses in real time display inside the angiography room". Cardiovas. Intervent. Radiol. 33 1210-1214.

Sempau, J., Badal, A., and Brualla L. 2011. "A PENELOPE-based system for the automated Monte Carlo simulation of clinacs and voxelized geometries--application to far-from-axis fields". Med. Phys. 38 5887-5895.

Struelens L, Carinou E, Clairand I, et al. 2011. "Use of active personal dosemeters in interventional radiology and cardiology: tests in hospitals e ORAMED project". Radiat Meas. 46 1258-1261.

Zankl, M., Fill, U., Petoussi-Henss, N. and Regulla, D. 2002. "Organ dose conversion coefficients for external photon irradiation of male and female voxel models". Phys. Med. Biol. 47 2367-2385. 